\title{
Research on the Present Situation and Development Strategy of Jiajiagou Village in Puge County
}

\author{
Tianlin Su \\ College of Architecture, Southwest Minzu University, Chengdu, China \\ Email: 962761697@qq.com
}

How to cite this paper: Su, T.L. (2021) Research on the Present Situation and Development Strategy of Jiajiagou Village in Puge County. Open Access Library Journal, 8: e7713.

https://doi.org/10.4236/oalib.1107713

Received: June 29, 2021

Accepted: July 27, 2021

Published: July 30, 2021

Copyright $\odot 2021$ by author(s) and Open Access Library Inc.

This work is licensed under the Creative Commons Attribution International License (CC BY 4.0).

http://creativecommons.org/licenses/by/4.0/

\section{(c) (i) Open Access}

\begin{abstract}
This study starts from the rural planning and design problems of Jiajiagou Village, Puge County, Liangshan Yi Autonomous Prefecture, Sichuan Province. Based on the analysis of its spatial texture, this study analyzes the current situation of its industrial development, infrastructure construction, cultural construction and other aspects in combination with the basic situation of the investigation. Through various investigations and studies, this paper revealed the planning and design effects and further interpreted existing problems of Jiajiagou Village, and targeted and effective suggestions were put forward to promote the development of Jiajiagou Village, so as to provide certain theoretical reference for the application of rural revitalization strategy in remote ethnic minority areas.
\end{abstract}

\section{Subject Areas \\ Development Economics}

\section{Keywords}

Jiajiagou Village, Current Situation Overview, Development Strategy

\section{Introduction}

In recent years, in the country, revitalization strategy "prosperous industry, ecological livable, local custom civilization, effective governance (Yu De, 2019) [1], rich life", five concepts under the guidance, relevant state departments and Yun, Gui, Chuan three provincial government departments at all levels have formulated a number of policies and documents, accelerated the pace of rural revitalization, vigorously promoted rural revitalization in the southwest of fully dep- 
loyed, Rural revitalization has become the main melody of rural development in today's times. Here scholars have researched a lot about village's development strategies based on the background of rural revitalization, but there are few researches on village development strategy in minority areas, therefore, based on the background of rural revitalization, this study starts from the rural planning and design problems of Jiajiagou Village, Puge County, Liangshan Yi Autonomous Prefecture, Sichuan Province (He Renwei, 2018) [2]. Based on the analysis of its spatial texture, this study analyzes the current situation of its industrial development, infrastructure construction, cultural construction and other aspects in combination with the basic situation of the investigation (Liang Aiwen, 2018) [3]. Through various investigations and studies, the planning and design effects and existing problems of Jiajiagou Village are further interpreted, and targeted and effective suggestions are put forward to promote the development of Jiajiagou Village, so as to provide certain theoretical reference for the application of rural revitalization strategy in remote ethnic minority areas.

\section{Research Methods}

\subsection{Literature Reference Method}

Read relevant literature and materials related to rural revitalization, county rural construction planning, rural planning system, village and town planning and village construction related urban and rural planning, human geography and other fields, summarize and analyze some previous research results, hoping to provide some reference and guidance for this paper. Through reading the relevant local literature and historical data, social and economic development status and construction data over the years, we have a basic understanding of the development of Jiajiagou Village in Puge County.

\subsection{Inductive and Deductive Analysis}

Based on the research of the related literature, the study of knowledge information summary, for the article fundamental research to make a good bedding, the practice of case study also let produced by generally to rise to the change of individual process, in this study a ditch the current actual situation, a nail groove rural construction planning for related research.

\subsection{Field Survey Method}

Field research is relative to desk research, is to carry out market research activities in the field collectively (Wang Jiao, 2018) [4]. In some cases, desk research can not meet the purpose of research, when the collection of information is not timely and accurate, it is necessary to timely conduct field research to solve problems, obtain first-hand information and information, so that the research work can be carried out effectively and smoothly. Field research refers to the investigation of first-hand information (Chen Mingliang, Zhao Zhen, Ma Qingguo, 2018) [5]. 


\section{Overview of the Study Area}

\subsection{Location Relationship}

Puge County is located in the southwest of Sichuan Province and the east of Liangshan Yi Autonomous Prefecture, between $27^{\circ} 13^{\prime}-27^{\circ} 30^{\prime} \mathrm{N}$ and $102^{\circ} 26^{\prime}$ $102^{\circ} 46^{\prime} \mathrm{E}$, covering an area of 1918 square kilometers (Figure 1). It borders Butuo, Ningnan, Dechang, Xichang and Zhaojue counties (cities) in the east, south, west, northwest and north respectively. Puji county town in the south of the county, is located in the provincial road west (chang) qiao (home) highway, north from the state capital of Xichang 74 kilometers. Jiajiagou village is located in the north of special bu township, the village committee is 6 kilometers away from the township government, the whole village covers an area of 7.74 square kilometers, and the cultivated land area is $2605 \mathrm{mu}$. It has jurisdiction over 5 villagers groups, 310 households and 1133 people. The entrance to the village is 598 meters away from the S212 Provincial Road, with convenient transportation. The village is surrounded by green hills on the north, south and east sides, and streams pass through the north and south sides. The resource conditions are superior.

\subsection{Green Water Vegetation and Roads}

Mainly in the primary industry, the villagers mainly to grow rice, wheat, corn, flue-cured tobacco. The main industries in the village are flue-cured tobacco, animal husbandry, labor export and traditional crops such as rice, wheat, corn and potato planting. There is a stream running from east to west in the village. In December 2018, the construction of the intra-village road was started and has been completely completed. The quality of the village road is good, the width of the road is $2-4$ meters, and the road between houses is completely hardened. The village entrance is 598 meters away from the S212 provincial road, with convenient transportation. The village is surrounded by green hills on the north, south and east sides.

\subsection{Current Population}

Jiajiagou village has five villager groups of 310 households with a population of

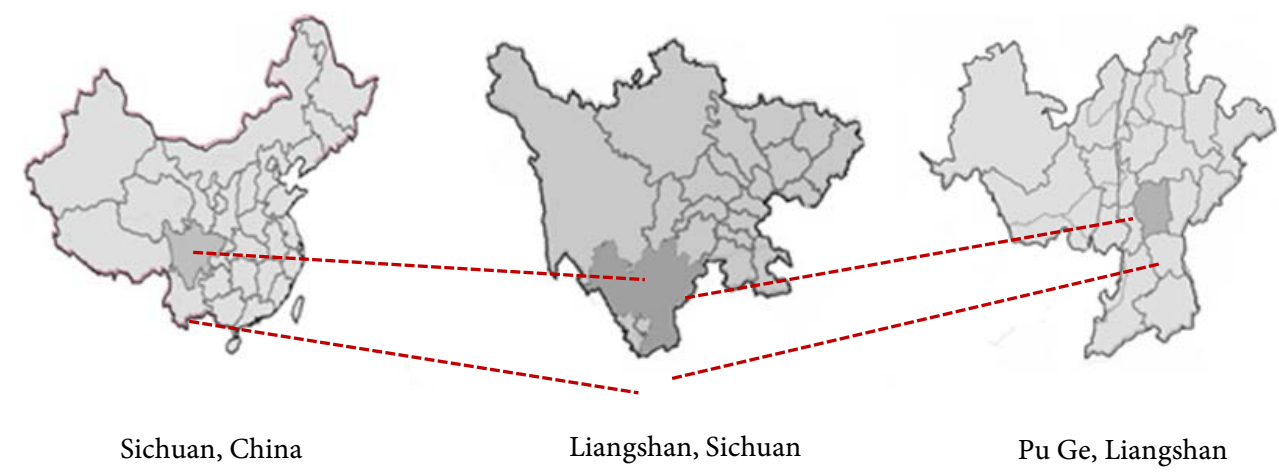

Figure 1. Location map of Jiajiagou Village (source: Self-photographed by the author). 
1133 people. The male to female ratio in the village is $1.5: 1$. At present, the population over 60 years old accounts for about $20 \%$ of the total population. It is expected that the population over 60 years old will continue to increase in the future, and the proportion will continue to increase. The demand for related facilities involving the elderly in the village is also increasing. The poverty rate of 120 households and 512 people in the village is $45 \%$, making it a deeply poverty-stricken village. Under the correct leadership of Party committees and governments at all levels and the help of all social forces (Tie Xingliang, 2019) [6], Jiajiagou Village has been lifted out of poverty in 2019 with 197 people of 49 households, and 315 people of 71 households in 2020. It will quit the poverty-stricken village in 2020 .

\subsection{Industry Overview}

Jiajiagou village economy is weak, mainly to the primary industry, the villagers mainly to planting rice, wheat, corn, flue-cured tobacco (Figure 2). The main industries in the village are flue-cured tobacco, animal husbandry, labor export and traditional crops such as rice, wheat, corn and potato cultivation. Almost every family has poultry and livestock. This year, the village planted 300 acres of flue-cured tobacco, 100 acres of winter peach, 80 acres of crisp red pear, red prickly ash base 3000 acres. On the whole, the primary industry develops well and increases the income of villagers, while the secondary and tertiary industries have a low level of development and need to be improved.

\subsection{Public Service Facilities}

A nail groove village public facilities along with the living group distribution, existing in the east village built by the three gorges company living service center between group a nail groove in the center of the village, covers an area of about 1500 square meters, with the village committee, village health hospital, men's and women's bathroom, dining room, basketball court, table tennis and fitness equipment for the villagers to entertainment (Figure 3). Between Group 1 and Group 2, there is an Agricultural Bank withdrawal point, a kindergarten (4 teachers), and a middle class, a big class and a preschool in the village kindergarten. In addition, Group 2 also has a village ethnic culture square and an activity square.
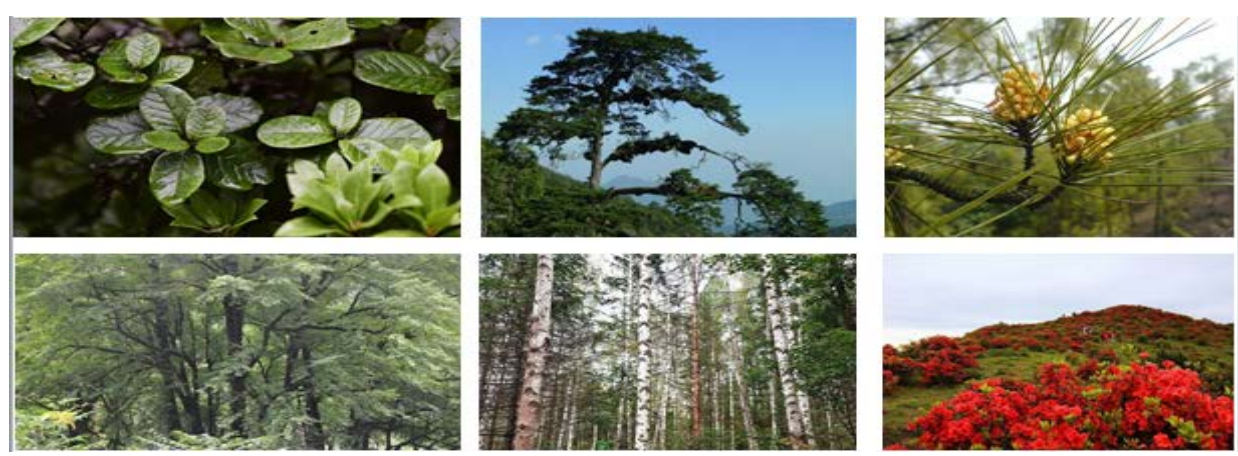

Figure 2. Vegetation (image source: Internet). 

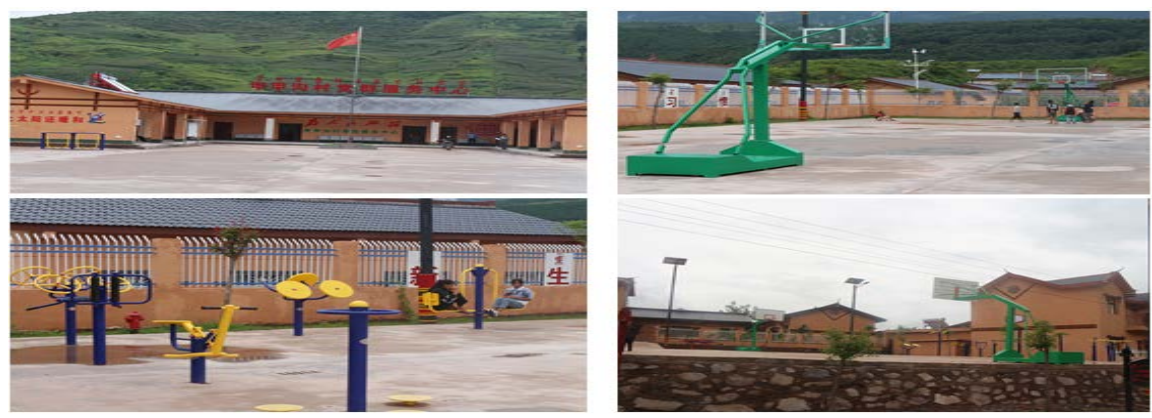

Figure 3. Infrastructure (source: Self-photographed by the author).

\section{Spatial Mechanism of Jiajagou Village}

The organizational content of mechanism is entity and space. Jiajagou Village is made up of two groups, one of which is the neatly arranged cluster built by the Three Gorges Company from the entrance of the village, and the other is the residential cluster built according to the topography and the Sichuan Provincial Tobacco Company (Figure 4). Village domain space textures for the most common dot ribbon distribution of southwest mountainous area, by the formation of long-term effects of topography on dendritic roads connect the residential areas, residential areas, more than in a grid road network layout, the second set of housing so relatively fragmented, and terrain built a group to focus on the road on both sides of the uniformity of the group (Figure 5). Most of the land in the village is agricultural and forestry land. Rice, wheat and corn are planted along the terrain, and flue-cured tobacco is planted in relatively flat areas. The architectural appearance of the village is unified. The architectural appearance is unified as a grey sloping roof. The facade of the building is sprayed with yellow paint with pink, and the wall body is painted with a totem with Yi characteristics composed of red, yellow and black. The residential buildings are mainly modern detached houses. One group has one floor and each family has its own yard for growing fruits and vegetables (Huang Zuhui, 2018) [7]. The other two groups are two-story houses built along the terrain and each family has an independent bathroom outside the yard.

\section{Current Situation of Jiajigou Village}

\subsection{Income and Employment}

Employment location: The current employment location is relatively concentrated, $50 \%$ of the villagers work in the village, $36 \%$ of the villagers work in the coastal cities outside the province, $8 \%$ of the villagers work in other cities outside the province Liangshan Prefecture, $4 \%$ of the villagers rely on financial subsidies for their livelihood, and $2 \%$ of the villagers do business (Figure 6). From the proportion analysis, it can be seen that the migrant workers in this village mainly consider to work in coastal cities outside the province, which reflects the general trend of urbanization. Per capita income: The per capita income of residents in this village is mostly less than 5000 yuan and 5000 - 10,000 yuan, accounting for 


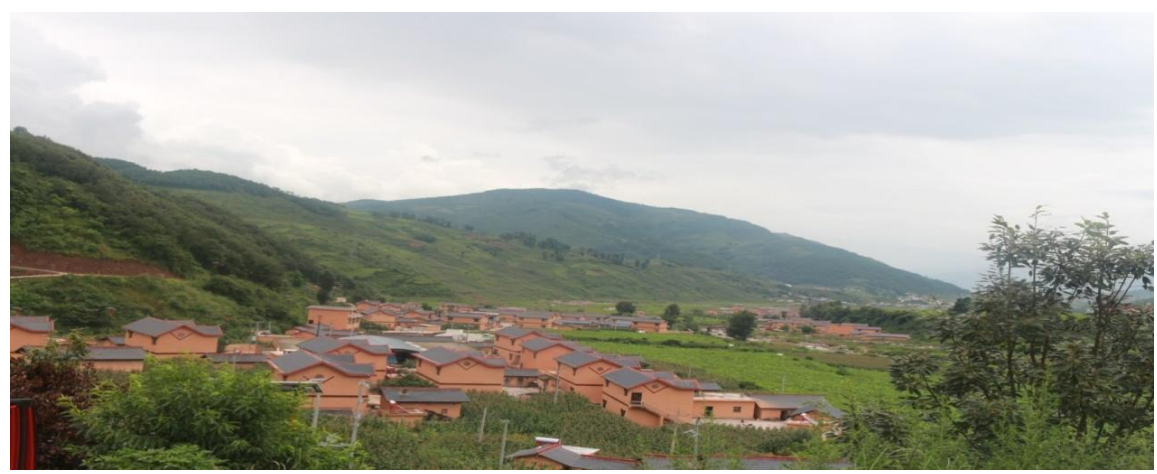

Figure 4. Picture of the status quo of Jiajiagou Village; source: Self-photographed by the author.

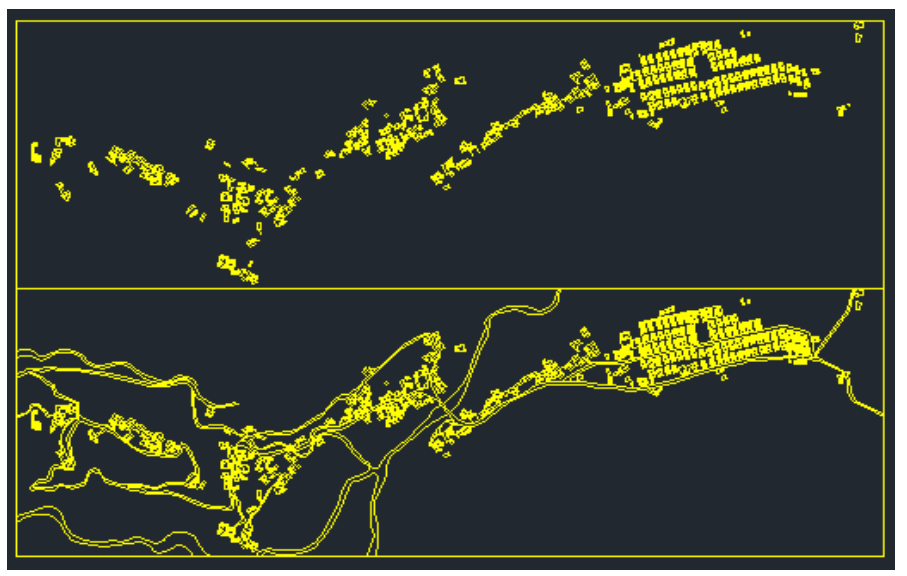

Figure 5. Distribution map of buildings in Jiajiagou Village; source: author's own drawing.

\section{The main source of your family income is?}

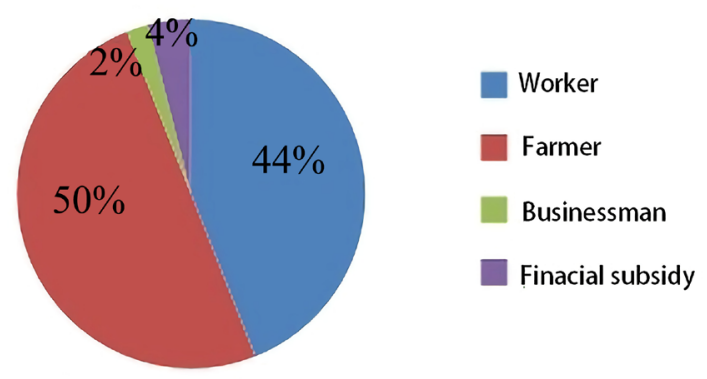

Figure 6. Questionnaire survey statistics, employment (source: author's own drawing).

$91 \%$ of the total proportion, of which the income of $5000-10,000$ yuan accounts for $43 \%$ (Figure 7 ).

\subsection{Living Conditions}

Living situation: the current Jiajiagou village is newly built single-family houses, 


\section{The per capita annual income of your family is?}

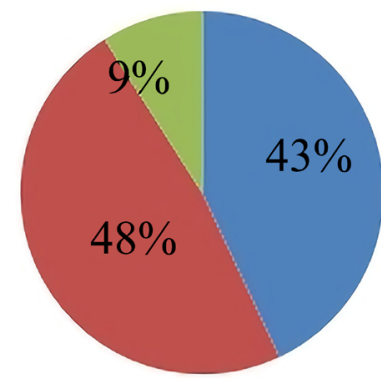

$<5000 \mathrm{RMB}$

5000-10000RMB

$>10000 \mathrm{RMB}$

Figure 7. Questionnaire survey statistics, income (source: author's own drawing).

most of which have 4 - 6 people, accounting for $40 \%$ of the total number of such households, about $30 \%$ of the total number of $2-4$ people, and $30 \%$ of the total number of more than 6 people. $95 \%$ of the villagers said they would keep their current residential houses unchanged in the next five years, $5 \%$ of the villagers said they would renovate their houses in the next five years, and no villagers planned to build new houses in the next five years. Living conditions: At present, the daily living expenses of villagers in Jiajagou Village are mainly for meals and children's schooling, of which $34 \%$ are for meals, $32 \%$ for children's schooling, $32 \%$ for daily medical expenses, and only $2 \%$ for entertainment (Figure 8 ). According to the survey, the villagers expressed the following five inconvenient places in life, among which daily leisure and cultural activities accounted for $27 \%$, school education accounted for $25 \%$, daily medical treatment accounted for $20 \%$, daily shopping accounted for $18 \%$ and daily going out accounted for $10 \%$ (Figure 9).

\subsection{Information on Various Types of Facilities}

Status a nail groove village village basic complete service facilities, but the extreme lack of cultural facilities, through the investigation, all kinds of facilities for the villagers of the importance of different, there are $30 \%$ of the villagers said medical facilities is important, there are $23 \%$ of the villagers who said that education facilities are important, there are $13 \%$ of the villagers who said fitness facilities are important, $20 \%$ of the villagers said cultural facilities is important, $6 \%$ of villagers said sanitation was important, and $6 \%$ said commerce was important (Figure 10). And villagers also need to improve the present situation of the facilities voted, accounted for $33 \%$ of the villagers said sewage processing is the most important, more important account for $19 \%$ of the villagers said water supply facilities, accounting for $10 \%$ of the villagers said the daily energy use gas is very important to improve, accounted for $8 \%$ of the villagers said the power supply is very important, and $30 \%$ of the villagers said communication and express post is more important (Figure 11). For the current environmental conditions in the 


\section{What is the main economic expenditure of your family?}

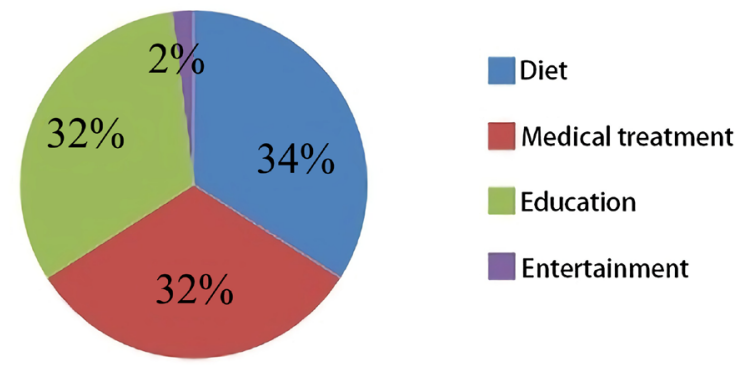

Figure 8. Questionnaire survey statistics, economic expenditure (source: author's own drawing).

\section{What do you think is inconvenient} in the village you live in?

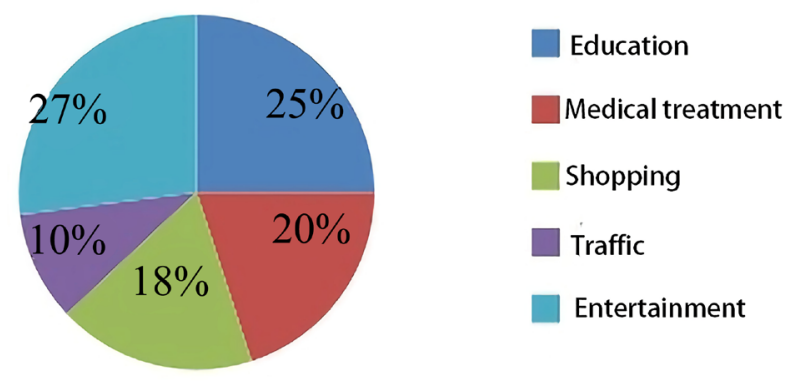

Figure 9. Questionnaire survey statistics, inconvenient places (source: author's own drawing).

\section{Which facilities in this village do you think is more important?}

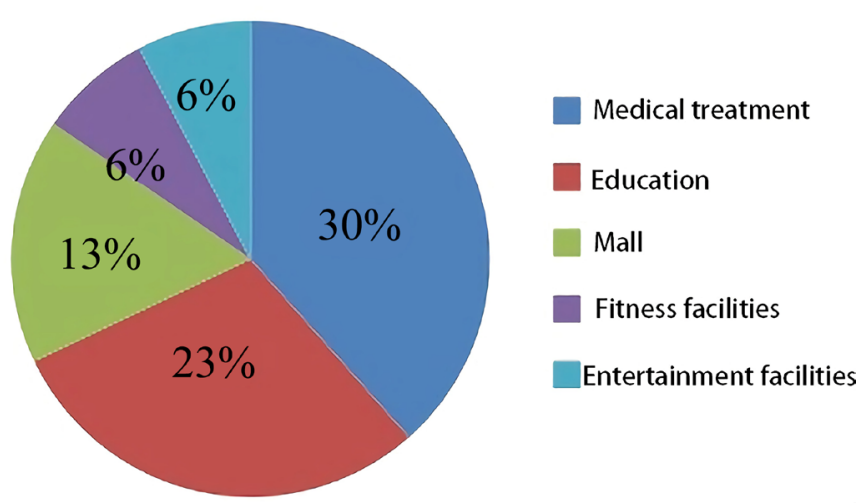

Figure 10. Questionnaire survey statistics, facilities (source: author's own drawing). 
village, the villagers also voted, accounting for $32 \%$ of the villagers said that the improvement of the appearance of the village should be continued, $25 \%$ of the villagers said that the garbage collection and transfer work should be urgently solved, $18 \%$ of the villagers said that the addition of squares and other activity venues should be urgently solved, $14 \%$ of the villagers said that the orderly greening of the village is the most important, $11 \%$ of the villagers said that the improvement of the Hang Tong water area was the most important (Figure 12).

According to the comprehensive survey results, in Jiajagou Village, the factors affecting the quality of life of villagers are mainly caused by the low income caused by economic backwardness. Secondly, the villagers need to urgently improve educational facilities, medical facilities, cultural facilities, village appearance and all kinds of infrastructure. Therefore, in order to meet the actual needs of villagers, the future planning of the village should take the exploration of industrial development and the increase of villagers' income as the macro planning focus, and the construction of infrastructure, the improvement of public facilities and the construction of cultural facilities as the focus of village construction (Zang Leizheng, 2016) [8].

What do you think needs to be improved about the village' s infrastructure?

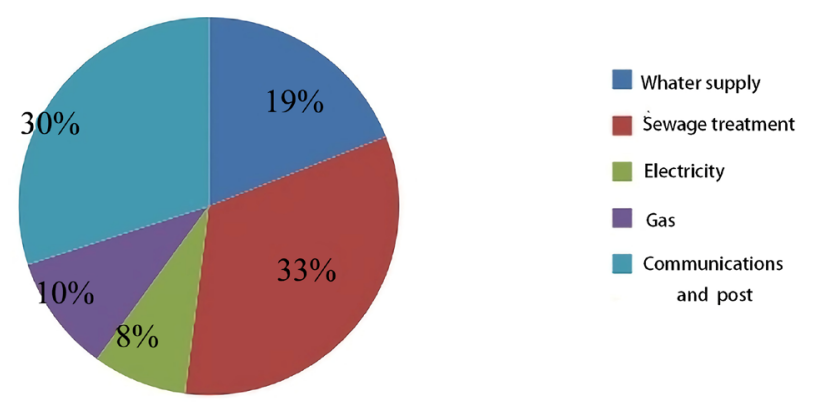

Figure 11. Questionnaire survey statistics, facilities (source: author's own drawing).

\section{What do you think needs to be improved in the village?}

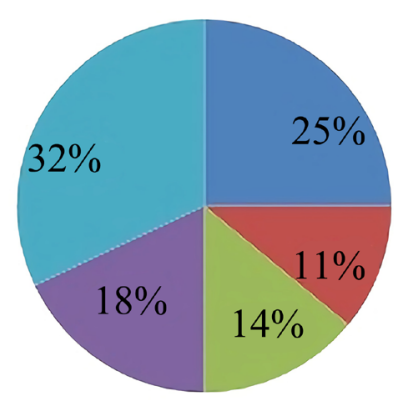

Garbage disposal

Renovation of ponds

Increase greening

Increase cultural venue

Figure 12. Questionnaire survey statistics, facilities (source: author's own drawing). 


\section{The Future Development Strategy of Jiajagou Village}

Through the investigation of Jiajia village, it was found that the villagers mainly planted rice, wheat, corn and flue-cured tobacco. The main industries in the village are flue-cured tobacco, animal husbandry, labor export and traditional crops such as rice, wheat, corn and potato planting. Jiajigou village industry is rich, but did not form a characteristic, the village should rely on Luoji mountain special town forestry park construction, vigorously develop breeding industry, explore tourism, Jiajiagou village into a combination of agriculture and tourism development mode of happy new village. To lay a solid foundation for the next step of rural revitalization.

The government should strengthen the policy support, and the local governments in minority areas should introduce relevant supportive policies in combination with the national policies, so as to arouse the enthusiasm of peasant households in developing characteristic industries by increasing the policy support and financial support.

Finally, it is also very important to further improve the information exchange channels and closely cooperate with the government and other departments at all levels. Through the construction of information exchange platforms such as websites, we can contact the masses and constantly expand the sales channels of agricultural products.

\section{Conclusion}

Through the in-depth investigation of Jiajiagou Village in Puge County, it is found that the factors affecting the quality of life of the villagers are mainly caused by the low income caused by economic backwardness. Secondly, the urgent improvement of the villagers also includes educational facilities, medical facilities, cultural facilities, village appearance and various infrastructures. Therefore, in order to meet the actual needs of villagers, the future planning of the village should take the exploration of industrial development and the increase of villagers' income as the macro planning focus, and the construction of infrastructure, the improvement of public facilities and the construction of cultural facilities as the focus of village construction (Liu Haoran, 2019) [9]. In the future development, the government should strengthen policy support and guide the development of local characteristic industries. Finally, it is also very important to constantly expand the sales channels of agricultural products.

\section{Conflicts of Interest}

The author declares no conflicts of interest.

\section{References}

[1] De, Y. (2019) Research on Xi Jinping's Targeted Poverty Alleviation Thought. Party School of the CPC Central Committee, Beijing.

[2] He, R.W. (2018) Urban-Rural Integration and Rural Revitalization: Theoretical 
Discussion, Mechanism Interpretation and Realization Path. Geographical Research, 37, 2127-2140.

[3] Liang, A.W. (2018) New Exploration on the Beautiful Rural Construction in Western Minority Areas from the Perspective of Rural Revitalization. Heilongjiang Minorities Series, No. 5, 48-55.

[4] Wang, J. (2018) Sustainable Tourism Poverty Alleviation in Minority Areas under the Rural Revitalization Strategy. Agricultural Economy, No. 8, 30-32.

[5] Chen, M.L., Zhao, Z. and Ma, Q.G. (2018) Social Science Research Methodology Innovation: Investigation, Analysis and Suggestions. Journal of Management Engineering, 32, 79-87.

[6] Tie, X.L. (2019) The Impact of Big Data Technology on Social Science Methodology. Harbin University of Science and Technology, Harbin.

[7] Huang, Z.H. (2018) Accurate Grasp of China's Rural Revitalization Strategy. Chinese Rural Economy, No. 4, 2-12.

[8] Zang, L.Z. (2016) The Application and Reflection of Experimental Methods in Social Science Research: A Case Study of Political Science. Journal of Renmin University of China, 30, 150-156.

[9] Liu, H.R. (2018) Comparative Research Methods in the Social Sciences: Development, Types and Debates. Science and Technology of CSRC, No. 1, 122-133. 